\title{
Potential impacts of climate change and humans on the trophic network organization of estuarine food webs
}

\author{
Catarina Vinagre ${ }^{1, *}$, Maria J. Costa ${ }^{1}$, Spencer A. Wood ${ }^{2}$, Richard J. Williams ${ }^{3}$, \\ Jennifer A. Dunne ${ }^{4}$ \\ ${ }^{1}$ MARE - Marine and Environmental Sciences Centre, Faculdade de Ciências, Universidade de Lisboa, Campo Grande, \\ 1749- 016 Lisboa, Portugal \\ ${ }^{2}$ School for Environmental and Forest Sciences, University of Washington, Seattle, WA 98195, USA \\ ${ }^{3}$ VibrantData Inc., 943 Clay Street, San Francisco, CA 94108, USA \\ ${ }^{4}$ Santa Fe Institute, 1399 Hyde Park Road, Santa Fe, New Mexico 87501, USA
}

\begin{abstract}
The aim of this study was to compare estuarine food web network structure in the past, present and future, in a climate warming context, while also taking the trophic role of humans into account. Three versions of the Tagus Estuary (Portugal) food web were compiled representing its past (1970s), present (2000s) and future (2100s) trophic organization in relation to losses and gains of taxa and feeding links due to climate change. Although the species richness of the Tagus Estuary food web is expected to increase from past to present to future, along with links and mean links per species, due to a net gain of primarily fish species, there is little anticipated change in the structure of the food web. Unlike all but a few previously published food webs, the Tagus dataset explicitly includes humans, and compared to other predators in the food web, humans are supergeneralists that feed on an increasing fraction of available taxa from the past to the future, up to $38 \%$ of species by the $2100 \mathrm{~s}$. Such an increase in human impact results from many of the projected new species being commercial species in their current range. In addition, a supergeneralist shark, the milkshark Rhizoprionodon acutus, is predicted to enter the system in the future under climate change. Since the milkshark is likely to have a similar diet to humans, it may amplify the pressure on species already under fishing pressure and alter the function and stability of the Tagus estuary food web. Similar phenomena can occur at other mid-latitude estuaries.
\end{abstract}

KEY WORDS: Niche model · Probabilistic niche model · Estuarine environments · Anthropogenic impact

\section{INTRODUCTION}

Estuaries are naturally dynamic and complex ecosystems that provide nursery habitats, spawning grounds, refuge from predators, and migratory routes for many species (McLusky 1981, Able 2005, Elliott \& Hemingway 2002). Being very productive (McLusky \& Elliott 2004, 2007), these ecosystems have long attracted human populations that settled around them and lived off the many resources they provide:

${ }^{*}$ Corresponding author: cmvinagre@fc.ul.pt

$\S$ Article was changed to Open Access, and the copyright notice updated after publication.

This corrected version: June 3, 2019 namely edible fish, crustaceans, cephalopods and bivalves. Human interaction with estuary and nearshore marine food webs over thousands of years has clearly impacted the abundance and diversity of species in these systems, as demonstrated for the Adriatic Sea (Lotze et al. 2011). The ecosystem of the present study, the Tagus Estuary (Portugal, $\mathrm{NE}$ Atlantic, $38^{\circ} \mathrm{N}, 8^{\circ} \mathrm{W}$ ), has long sustained important fisheries and fishing communities and is currently surrounded by a population of 2 million people.

(C) The authors 2019. Open Access under Creative Commons by Attribution Licence. Use, distribution and reproduction are unrestricted. Authors and original publication must be credited.

Publisher: Inter-Research · www.int-res.com 
Several studies have reported that its species composition has been going through alterations since the 1970s, probably related to climate change, resulting in both species losses and the addition of new species (Cabral \& Costa 1999, Cabral et al. 2001, Vinagre et al. 2007, 2009). Such changes in species composition have the potential to alter the structure and functioning of the food web. Theoretical food web models predict that food web structure, and in particular connectance, should be sensitive to warming (e.g. Petchey et al. 2010). Many other studies have described and compared the structural network properties of complex food webs in a variety of natural terrestrial and aquatic ecosystems (e.g. Petchey et al. 1999, Williams \& Martinez 2000, Camacho et al. 2002, Dunne et al. 2002a, 2004, Krause et al. 2003, Stouffer et al. 2005, 2007, Woodward et al. 2010), including extension to ancient food webs (Dunne et al. 2008, 2014) and food webs that include parasites (Dunne et al. 2013). In the case of marine webs, Cohen (1994) and Link (2002) suggested that they have different structure than food webs from other habitats. The marine food webs thus far compiled do appear to have relatively high connectance (links/ species $^{2}$, the proportion of possible links that are realized) compared to other types of webs; however, Dunne et al. (2004) demonstrated that, like other food webs, marine webs do not have different structure than expected given their diversity and complexity, which held true also for intertidal webs with or without inclusion of parasites (Dunne et al. 2013). The simple comparison of raw property values across food webs (e.g. Link 2002) is misleading because those values are scale-dependent on the diversity $(S$, species richness) and the complexity $(C$, connectance) of the web being analysed (Wood et al. 2015). Instead, approaches such as niche modelbased analyses (Williams \& Martinez 2000) allow comparison of the structure of food webs with different levels of diversity and complexity (e.g. Dunne et al. 2004, 2013). Such studies have generally corroborated the finding that food webs from different ecosystems share fundamentally similar structure and organization characteristics. However, there has yet been no assessment of the past, current, and projected future impacts of climate change on the structure of the food web for a particular habitat.

Another frontier in food web studies is the explicit inclusion of humans as nodes in highly resolved ecological networks, which allows exploration of their roles in and impacts on ecosystems in light of the myriad connections among species, including Homo sapiens (Dunne et al. 2016, Crabtree et al. 2017). Pre- vious work has focused on pre-modern huntergatherers (Dunne et al. 2016) and agriculturalists (Crabtree et al. 2017). One prior study included modern humans as a node in a reasonably well-resolved marine food web (81 taxa) for the Northeast US Shelf (Link 2002) but did not conduct any analyses related to human roles in that food web.

The present work uses several versions of the Tagus Estuary food web to assess whether and how its network structure is changing over time in relation to climate change impacts on particular taxa. Three versions of the recently compiled and highly resolved Tagus Estuary food web (Vinagre et al. 2017) - a historical food web from the 1970s, the current web of the 2000s, and the projected food web for the $2100 \mathrm{~s}$ - are compared to each other and to webs from other intertidal systems using standard and probabilistic niche model analyses (Williams \& Martinez 2000, Williams \& Purves 2011, Dunne et al. 2013). In addition, we assess the trophic roles of humans in the past, present, and future Tagus Estuary webs compared to other taxa in the food web.

\section{MATERIALS AND METHODS}

\subsection{The Tagus Estuary food web: past, present and future}

Three Tagus Estuary food webs were constructed to represent past (1970s), present (2000s), and future (2100s) communities. The 1970s and 2000s represent the time points when the estuary had its most complete sampling and thus offer the most reliable data for creating highly defined trophic networks. Taxa included in the past and present food webs were based on recorded occurrences in taxonomic surveys every 2 mo from 1978-1981 and 2000-2002 of fish, crabs, shrimp and cephalopods (Costa \& Bruxelas 1989, Cabral \& Costa 1999, Cabral et al. 2001, Costa et al. 2007, Vinagre et al. 2006, 2007, 2009), macroalgae (Sousa-Dias \& Melo 2008), phytoplankton (Ribeiro et al. 2003, Tolhurst et al. 2003, Brogueira et al. 2007), zooplankton (Marques et al. 2006), benthic macroinvertebrates (Gaudêncio \& Cabral 2007, Chaínho et al. 2008), birds (Moreira 1997, 1999), and fish parasites (Durieux et al. 2007). The present-day food web (previously analyzed in different ways by Vinagre \& Costa 2014, Vinagre et al. 2017) excluded taxa that were absent (or extremely rare $=1$ individual) in the 1995-1997 surveys and that remained absent in the 2000-2002 surveys (Table 1). The future food web for the year 2100 was created by 
Table 1. Species that were lost or added to the Tagus Estuary food webs (0: absent; 1 : present)

\begin{tabular}{|c|c|c|c|c|}
\hline Species & Common names & $\begin{array}{c}\text { Past } \\
1978-1981\end{array}$ & $\begin{array}{c}\text { Present } \\
2000-2002\end{array}$ & $\begin{array}{c}\text { Future } \\
2100\end{array}$ \\
\hline Ciliata mustela & Fivebeard rockling & 1 & 0 & 0 \\
\hline Platichthys flesus & European flounder & 1 & 0 & 0 \\
\hline Sprattus sprattus & Sprat & 1 & 0 & 0 \\
\hline Argyrosomus regius & Meagre & 0 & 1 & 1 \\
\hline Arnoglossus laterna & Mediterranean scaldfish & 0 & 1 & 1 \\
\hline Diplodus bellottii & Senegal seabream & 0 & 1 & 1 \\
\hline Eriocheir sinensis & Chinese mitten crab & 0 & 1 & 1 \\
\hline Halobratrachus didactylus & Lusitanian toadfish & 0 & 1 & 1 \\
\hline Raja clavata & Thornback ray & 0 & 1 & 1 \\
\hline Sparus aurata & Gilthead seabream & 0 & 1 & 1 \\
\hline Brachydeuterus auritus & Bigeye grunt & 0 & 0 & 1 \\
\hline Callionymus risso & Risso's dragonet & 0 & 0 & 1 \\
\hline Ethmalosa fimbriata & Bonga shad & 0 & 0 & 1 \\
\hline Mugil capurrii & Leaping African mullet & 0 & 0 & 1 \\
\hline Pseudotolithus senegalensis & Cassava croaker & 0 & 0 & 1 \\
\hline Pseudotolithus typus & Longneck croaker & 0 & 0 & 1 \\
\hline Pseudupeneus prayensis & West African goatfish & 0 & 0 & 1 \\
\hline Rhizoprionodon acutus & Milkshark & 0 & 0 & 1 \\
\hline Trachurus trecae & Cunene horse mackerel & 0 & 0 & 1 \\
\hline
\end{tabular}

modifying the fish community of the present food web based on predicted effects of climate change on the ranges of species on the Portuguese coast by Vinagre et al. (2011). Vinagre et al. (2011) estimated range shifts under the A2 scenario of the Special Report on Emission Scenarios (Nakicenovic et al. 2000), coupled with a regional circulation model predicting $2^{\circ} \mathrm{C}$ of sea-surface warming (Table 1). None of the fish species predicted by Vinagre et al. (2011) to move out of the study region inhabit the Tagus Estuary, so no species were lost from the future food web (Table 1). All other taxa presently living in the Tagus Estuary were assumed to exist in the future. Humans were included in all 3 food webs as predators of commercial species of fish, crustaceans, cephalopods, bivalves, and polychaetes (as bait). Trophic interactions between taxa were determined based on direct evidence (gut contents and observation of feeding behavior) from previously published studies conducted in the Tagus Estuary and elsewhere (Table S1 in the Supplement at www.intres.com/articles/suppl/m616p013_supp.pdf).

The original versions of the food webs were aggregated into trophic species versions, where nodes are taxa with identical sets of predators and prey (Briand $\&$ Cohen 1984). This convention reduces potential biases associated with uneven taxonomic resolution among taxa in food webs and allows use of modelbased food web analyses like the ones conducted here (e.g. Williams \& Martinez 2000, Dunne et al. 2013).

\subsection{Roles of humans in Tagus Estuary food webs}

To compare the roles of humans in the 3 versions of the Tagus Estuary food webs to other species in those webs, we calculated generality (Gen: the number of resource species), mean shortest path length (Path: the mean of the shortest chain of feeding interactions, regardless of direction, between each pair of species in the food web), and trophic level (SWTL: short-weighted trophic level; Williams \& Martinez 2004) for each species in the 3 webs. These properties were analyzed in detail because they allow an assessment of the trophic impact of humans, a top predator in this ecosystem.

\subsection{Comparative analysis of food webs}

Properties of the past, present, and future Tagus Estuary food webs were compared to each other and to 9 other published estuary and intertidal food webs. Five of the published webs are located in North America: Chesapeake, VA, USA; Carpinteria, CA, USA; Saint Mark's estuary, FL, USA; Estero de Punta Banda, Baja California, Mexico; and Bahía Falsa in Bahía San Quintín, Baja California, Mexico (Dunne et al. 2004). Three are located in Europe: Flensburg Fjord, Germany (Zander et al. 2011); Sylt Tidal Basin, Denmark (Thieltges et al. 2011); and the Ythan estuary, Scotland (Huxham et al. 1996). One was in New Zealand, Otago Harbour (Mouritsen et al. 2011). 
Details of the habitats, data collection protocols, and data are described by Hechinger et al. (2011), Mouritsen et al. (2011), Thieltges et al. (2011) and Zander et al. (2011). The Carpinteria and Otago Harbour food webs are more diverse versions of webs published previously (Thompson et al. 2005, Lafferty et al. 2006). All webs were compiled systematically from the outset to be comprehensive and highly resolved. Although these 9 other estuarine food webs do not include humans, comparisons with the Tagus Estuary are still justified as the inclusion or exclusion of one or a few nodes and their links in a complex food web does not significantly shift the organization of food webs or the metrics used to quantify their structure (Dunne et al. 2002b, 2008). We performed comparative analyses of food web properties for the Tagus Estuary, with and without humans, that confirms this for the food web networks investigated in the present work (Table S2).

For each food web, 3 simple measures of node and link diversity and their relationships are reported: species richness $(S)$, links per species $(L / S)$, which is the mean number of predators and prey of nodes (also referred to as link density), and connectance $(C)$, the proportion of possible links that are realized $\left(C=L / S^{2}\right)$. We calculated 14 network structure properties: the fractions of top, intermediate, and basal taxa (Top, Int, Bas); the fractions of cannibals, herbivores, and omnivores (Can, Herb, Omn); the fraction of taxa that occur in loops, excluding cannibals (Loop); the standard deviations of normalized total links, generality, and vulnerability (LinkSD, GenSD, and VulSD); the mean short-weighted trophic level of all species (TL); the mean maximum trophic similarity of species (MaxSim); the mean shortest number of links between species pairs (Path); and the mean clustering coefficient (Clus). Refer to Table 1 in Dunne et al. (2013) for more detailed explanation of network structure properties.

To account for expected scale-dependent differences in network structure due simply to differences in the numbers of species and links of the empirical food webs, we used the niche model to create sets of simulated food webs with the same number of taxa and links as each empirical web (Williams \& Martinez 2000). The niche model has 2 input parameters: the number of trophic species $(S)$ and the connectance $(C)$ of the food web. The niche model assigns each taxon a randomly drawn 'niche value' $\left(n_{i}\right)$ from the interval $(0,1)$. Each consumer species is constrained to consume all resource species whose niche values fall within a range $\left(r_{i}\right)$ drawn from a beta distribution whose center $\left(C_{i}\right)$ is less than the con- sumer's niche value. The niche model allows up to half of a consumer's feeding range to include species with higher niche values than the consumer, thus allowing for some looping and cannibalism, which are observed in empirical food webs. For each empirical food web, we generated 1000 niche model webs with the same $S$ and $C$ as that web. We calculated model error (ME), the normalized difference between the model's median value across the set of 1000 webs and the empirical value for the actual corresponding food web. ME $>|1|$ indicates that the empirical property falls outside the most likely $95 \%$ of model values, with negative and positive MEs indicating model underestimation and overestimation of the empirical value, respectively (Dunne et al. 2013).

In addition, a probabilistic version of the niche model (PNM) was applied to the 3 Tagus Estuary webs, the 9 other estuarine webs, and 9 previously studied non-estuarine food webs (Bridge Brook Lake, Skipwith Pond, Benguela Marine, Coachella Desert, St. Martin Island, Caribbean Reef, NE U.S. Shelf Marine, Little Rock Lake, and El Verde Rain Forest, as in Dunne et al. 2004), following methods described by Williams et al. (2010) and Williams \& Purves (2011). The PNM produces a maximum likelihood estimate (MLE) of the fundamental niche model parameters for each species $i$ in a given web: its niche position $n_{i}$, its feeding position $c_{i}$, and its feeding range $r_{i}$. This allows computation of the probability of each link in a food web according to the model, and the overall expected fraction of links in a web predicted correctly $\left(f_{\mathrm{L}}\right)$. This fraction provides an easily understood measure of the overall performance of the model (Petchey et al. 2008, Williams \& Purves 2011).

\section{RESULTS}

Three cold water fish species that existed in Tagus Estuary in the 1970s were no longer present in the 2000s: the sprat Sprattus sprattus, the fivebeard rockling Ciliata mustela, and the European flounder Platichthys flesus (Table 1). Meanwhile, 6 fish species colonized Tagus Estuary during the same period - the tornback ray Raja clavata, the Lusitanian toadfish Halobatrachus didactylus, the meagre Argyrosomus regius, the gilthead seabream Sparus aurata, the Senegal seabream Diplodus bellottii, and the Mediterranean scaldfish Arnoglossus laternaand one invasive crab species, the Chinese mitten crab Eriocheir sinensis (Table 1). Vinagre et al. (2011) predicted that the Tagus Estuary food web will 
include 9 additional fish species in the 2100s: the milkshark Rhizoprionodon acutus, the Cunene horse mackerel Trachurus trecae, the Bonga shad Ethmalosa fimbriata, the Cassava croaker Pseudotolithus senegalensis, the longneck croaker Pseudotolithus typus, the West African goatfish Pseudopeneus prayensis, the dragonet Callionymus risso, the Leaping African mullet Mugil capurrii, and the bigeye grunt Brachydeuterus auritus (Table 1). These data informed the composition of the past and future Tagus Estuary food webs relative to what currently lives there.

A total of 455 species were observed in the Tagus Estuary during taxonomic surveys. Some species were aggregated due to uncertainty in predators' diets, which precluded the construction of prey-predator links at the species level for those taxa. This was particularly true for phytoplankton, zooplankton, and macrobenthic species, as is often the case for these types of organisms in food web data. The resulting past, present, and future Tagus Estuary food webs (Fig. 1) have 125, 129, and 138 taxa, resulting in webs with 100, 104, and 114 trophic species, respectively. The original number of taxa, trophic species $(S)$, and links per species $(L / S)$ of the Tagus estuary webs trended upward from the past to the future, while connectance $(C)$ remained relatively unchanged (Table 2). Taxa and $S$ values for the Tagus webs were higher than those reported for the 9 additional estuary/intertidal webs used for comparison, with the exception of Punt and Sylt, while $L / S$ and $C$ were within the same range (Table 2).

The top 10 taxa in each version of the Tagus Estuary food web for 3 species-level properties (Gen, Path, SWTL) are provided in Tables 3-5. In all 3 webs, Homo sapiens are the most generalist feeders (Gen), feeding on 40,45 , and 52 taxa in the past, present, and future webs, respectively, which represents 32,35 , and $38 \%$ of available taxa in those webs. Humans far exceed the generality of the next more generalist taxon in the past and present websPomatoschistus minutus in the past web (17 resources, $14 \%$ of total taxa), Raja clavata in the present web (19 resources, 15\% of total taxa) (Table 3, Fig. 2). A predicted addition to the future web, Rhizoprionodon acutus, is closer in generality to humans than other taxa and has a similar diet of 42 resources or $30 \%$ of total taxa. The mean generality of taxa in the past, present, and future webs increases from 5.09 to 5.29 to 5.54 . The 3 taxa with the shortest mean path lengths (Path) to other taxa in all 3 webs are Polychaeta, Bivalvia, and Amphipoda. Homo sapiens have the $7^{\text {th }}, 5^{\text {th }}$, and $4^{\text {th }}$ mean shortest path lengths in
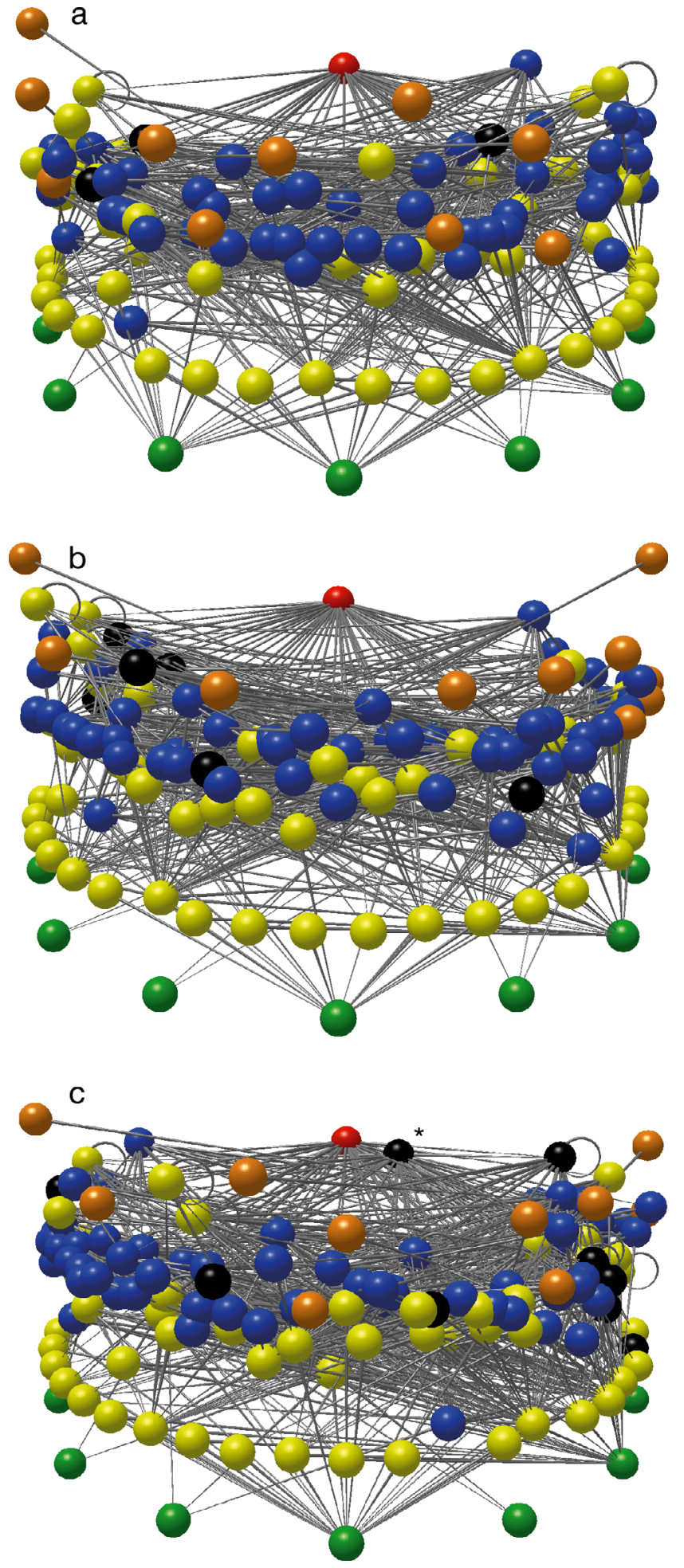

Fig. 1. The Tagus Estuary (a) past, (b) present and (c) future trophic species food webs. Green nodes: basal taxa; lime green nodes: invertebrates; blue nodes: vertebrates; orange nodes: parasites; red nodes: humans; milkshark is indicated by an asterisk. Black nodes in the Tagus past food web show species that are lost in the present; black nodes in the Tagus present and future webs show species not present in the past web 
Table 2. Values of original numbers of taxa (Taxa), trophic species $(S)$, links per species $(L / S)$, and connectance $(C)$ for 3 Tagus Estuary webs (past, present, future) and 9 additional estuary/intertidal webs. Webs are shown in order of increasing $S$ across the 3 Tagus webs and separately across the 9 other published webs

\begin{tabular}{|lrrrr|}
\hline Food web & Taxa & $S$ & $L / S$ & $C$ \\
\hline Tagus past & 125 & 100 & 5.81 & 0.06 \\
Tagus present & 129 & 104 & 6.03 & 0.06 \\
Tagus future & 138 & 114 & 6.22 & 0.05 \\
Chesapeake Bay & 33 & 31 & 2.23 & 0.07 \\
St. Marks Estuary & 48 & 48 & 4.60 & 0.10 \\
Flensburg Fjord & 77 & 56 & 6.39 & 0.11 \\
Bahia Falsa & 119 & 80 & 6.46 & 0.08 \\
Ythan Estuary & 92 & 82 & 4.82 & 0.06 \\
Carpinteria Salt Marsh & 107 & 91 & 8.46 & 0.09 \\
Otago Harbor & 123 & 96 & 7.99 & 0.08 \\
Estero de Punta Banda & 138 & 104 & 10.07 & 0.10 \\
Sylt Tidal Basin & 126 & 117 & 8.49 & 0.07 \\
\hline
\end{tabular}

the past, present, and future webs which is related to their high generality (Table 4). Mean Path changes very little across the 3 webs $(2.30,2.20$, and 2.27 in past, present, and future, respectively). The top 8 taxa with the highest trophic levels (SWTL) are stable across the 3 webs (Acanthocephalus clavula, Nematoda, Gyrodactylus elegans, Prosorhynchus crucibulum, Timoniella, Prosorhynchus aculeatus, Cucullanellus minutus, and Hydrozoa), with humans having the $10^{\text {th }}$ highest trophic level $(3.80)$ in the past and $9^{\text {th }}$ highest (3.84 and 3.83, respectively) in the present and future webs (Table 5). Mean trophic level changes very little across the 3 webs $(2.94,2.98$, and 2.97, respectively).

Niche model analyses of 14 network structure properties suggest that the Tagus Estuary food webs are structurally similar to each other through time (Fig. 3), with 2 exceptions. First, the present Tagus

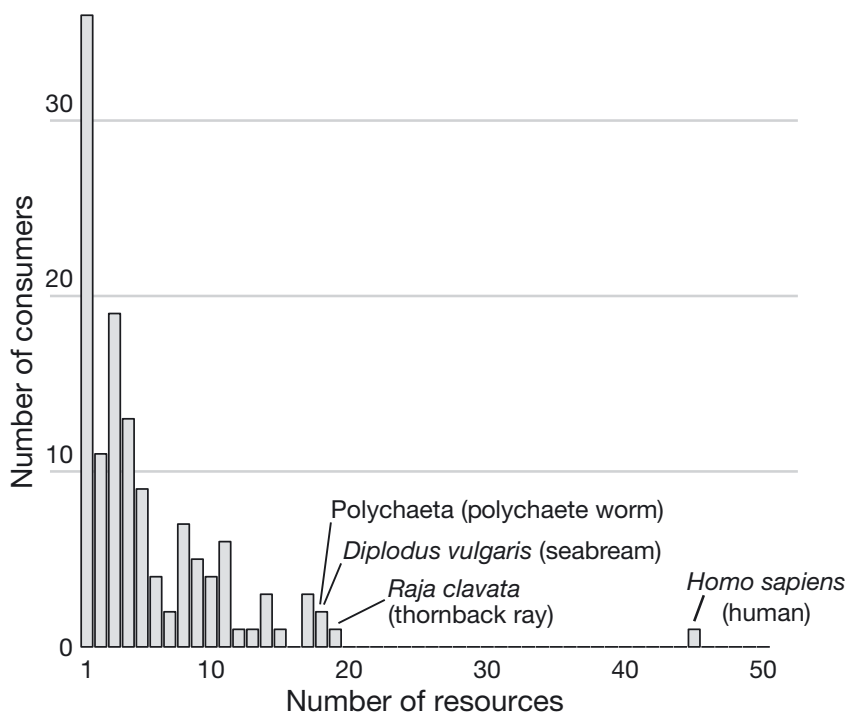

Fig. 2. Number of resource taxa per consumer for the original species version of the present Tagus Estuary food web. The vertical axis shows the number of consumers in that web that have a particular number of resource taxa, indicated along the horizontal axis. The 4 most generalist taxa are labeled by Latin name (common name)

web displayed higher model error (ME) for Path than future and past Tagus webs, indicating a shorter mean path length in that web compared to the other two. However, Path for all of the Tagus webs falls within the standard error for the 9 other intertidal/estuary webs. Second, the future Tagus web displayed much lower ME for Loop than the other webs, indicating much higher levels of looping than Tagus past and present webs. Compared to previously published estuarine/intertidal food webs, the MEs for the Tagus webs fall within the confidence intervals seen across the 9 other estuary/intertidal webs for most properties. Only 5 of the 14 properties show consistent divergence between the Tagus and

Table 3. Top 10 taxa with highest generality (Gen: no. of resource taxa fed on) for the past, present and future Tagus Estuary webs

\begin{tabular}{|llllll|}
\hline Rank & Past & Gen & Present & Gen & Future \\
\hline 1 & Homo sapiens & 40 & Homo sapiens & 45 & Homo sapiens \\
2 & Pomatoschistus minutus & 17 & Raja clavata & 19 & Rhizoprionodon acutus \\
3 & Phalacrocorax carbo & 17 & Diplodus vulgaris & 18 & Raja clavata \\
4 & Diplodus vulgaris & 17 & Polychaeta & 18 & Raja undulata \\
5 & Polychaeta & 17 & Raja undulata & 17 & Pomatoschistus minutus \\
6 & Raja undulata & 16 & Pomatoschistus minutus & 17 & Phalacrocorax carbo \\
7 & Engraulis encrasicolus & 15 & Phalacrocorax carbo & 17 & Diplodus vulgaris \\
8 & Trisopterus luscus & 15 & Engraulis encrasicolus & 15 & Polychaeta \\
9 & Platichthys flesus & 14 & Trisopterus luscus & 14 & Pseudotolithus senegalensis \\
10 & Ciliata mustela & 14 & Halobatrachus didactylus & 14 & Engraulis encrasicolus \\
\hline
\end{tabular}


Table 4. Top 10 taxa with lowest mean shortest path lengths (Path) across pairs of taxa for the past, present and future Tagus Estuary webs

\begin{tabular}{|c|c|c|c|c|c|c|}
\hline Rank & Past & Path & Present & Path & Future & Path \\
\hline 1 & Polychaeta & 1.40 & Polychaeta & 1.41 & Polychaeta & 1.43 \\
\hline 2 & Bivalvia & 1.50 & Bivalvia & 1.50 & Bivalvia & 1.52 \\
\hline 3 & Amphipoda & 1.62 & Amphipoda & 1.62 & Amphipoda & 1.64 \\
\hline 4 & Gastropoda & 1.74 & Gastropoda & 1.73 & Homo sapiens & 1.69 \\
\hline 5 & Copepoda & 1.79 & Homo sapiens & 1.76 & Gastropoda & 1.72 \\
\hline 6 & Crangonidae & 1.80 & Crangonidae & 1.79 & Copepoda & 1.78 \\
\hline 7 & Homo sapiens & 1.81 & Copepoda & 1.80 & Rhizoprionodon acutus & 1.80 \\
\hline 8 & Carcinus maenas & 1.88 & Pomatoschistus minutus & 1.89 & Crangonidae & 1.80 \\
\hline 9 & Pomatoschistus minutus & 1.91 & Carcinus maenas & 1.89 & Carcinus maenas & 1.89 \\
\hline 10 & Palaemonidae & 1.91 & Palaemonidae & 1.91 & Pomatoschistus minutus & 1.90 \\
\hline
\end{tabular}

Table 5. Top 10 taxa with highest trophic levels (SWTL: short-weighted trophic level) for the past, present and future Tagus Estuary webs

\begin{tabular}{|llcllll|}
\hline Rank & Past & SWTL & Present & SWTL & Future \\
\hline 1 & Acanthocephalus clavula & 4.59 & Acanthocephalus clavula & 4.62 & Acanthocephalus clavula & 4.59 \\
2 & Nematoda & 4.59 & Nematoda & 4.62 & Nematoda & 4.59 \\
3 & Gyrodactylus elegans & 4.30 & Gyrodactylus elegans & 4.32 & Gyrodactylus elegans & 4.30 \\
4 & Prosorhynchus crucibulum & 4.30 & Prosorhynchus crucibulum & 4.32 & Prosorhynchus crucibulum & 4.30 \\
5 & Timoniella & 4.30 & Timoniella & 4.32 & Timoniella & 4.30 \\
6 & Prosorhynchus aculeatus & 4.30 & Prosorhynchus aculeatus & 4.32 & Prosorhynchus aculeatus & 4.30 \\
7 & Cucullanellus minutus & 4.30 & Cucullanellus minutus & 4.32 & Cucullanellus minutus & 4.30 \\
8 & Hydrozoa & 4.00 & Hydrozoa & 3.96 & Hydrozoa & 4.00 \\
9 & Phalacrocorax carbo & 3.82 & Homo sapiens & 3.84 & Homo sapiens \\
10 & Homo sapiens & 3.80 & Phalacrocorax carbo & 3.84 & Phalacrocorax carbo \\
\end{tabular}

Fig. 3. Niche model errors (ME) for 14 network structure properties for 3 Tagus Estuary webs and 9 other estuary/intertidal webs: the fractions of top, intermediate, and basal taxa (Top, Int, Bas); the fractions of cannibals, herbivores, and omnivores (Can, Herb, Omn); the fraction of taxa that occur in loops, excluding cannibals (Loop); the standard deviations of normalized total links, generality, and vulnerability (LinkSD, GenSD, and VulSD); the mean short-weighted trophic level of all species (SWTL); the mean maximum trophic similarity of species (MaxSim); the mean shortest number of links between species pairs (Path); and the mean clustering coefficient (Clust). MEs > |1| indicate a poor fit of the niche model prediction to the empirical value. Negative MEs indicate niche model underestimation of the property value; positive MEs indicate niche model overestimation of the property value. Past, present and future Tagus Estuary webs are represented by circles, squares, and diamonds, respectively. Error bars show the $97.5 \%$ probability range from a $t$ distribution given 8 degrees of freedom

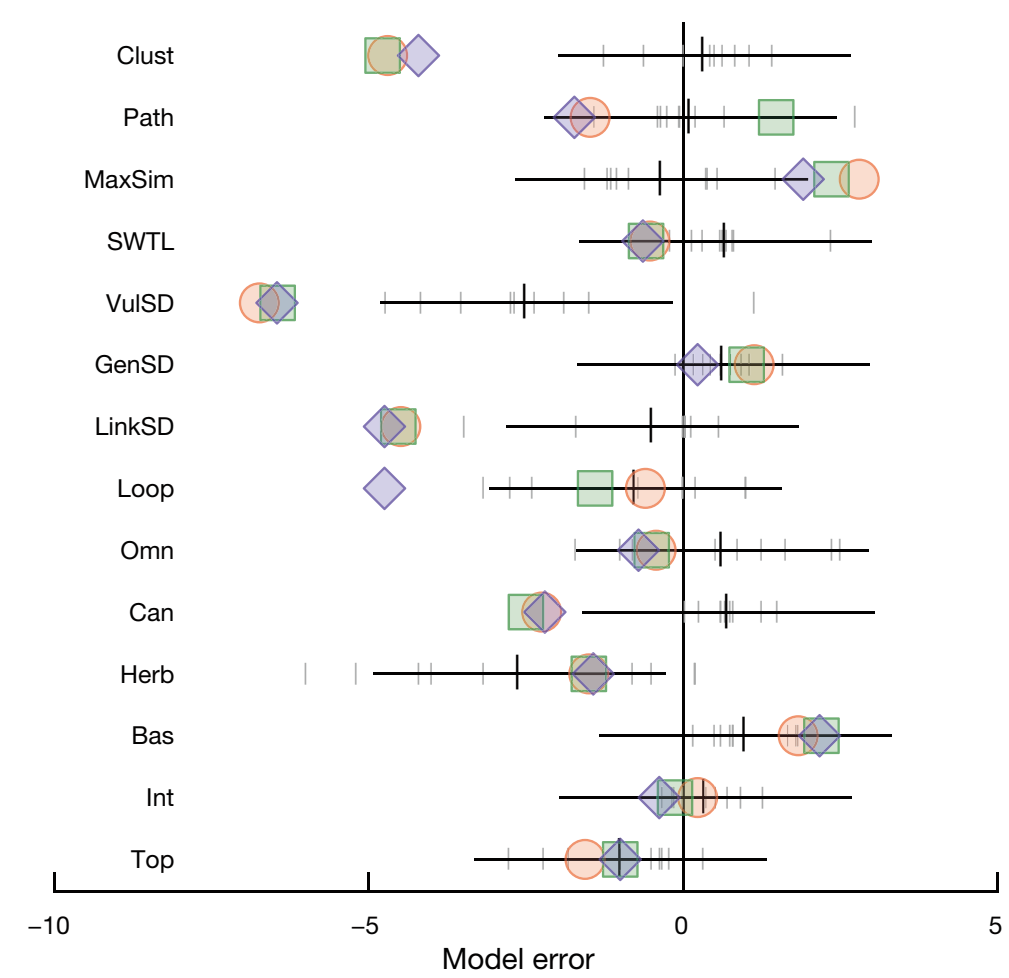


Table 6. Fraction of the 14 structural network properties that are predicted correctly by the niche model $(\mathrm{ME}<|1|)$ and the fraction of the links predicted correctly by the 1-dimensional probabilistic niche model $\left(f_{\mathrm{L}}\right)$ for the 3 Tagus Estuary food webs and 9 other estuarine food webs. Webs are shown in order of increasing $S$ across the 3 Tagus webs (past, present, future) and separately across the 9 other webs

\begin{tabular}{|lcc|}
\hline Food Web & $\mathrm{ME}<|1|$ & $f_{\mathrm{L}}$ \\
\hline Tagus past & 0.33 & 0.52 \\
Tagus present & 0.40 & 0.54 \\
Tagus future & 0.47 & 0.53 \\
Chesapeake Bay & 0.69 & 0.81 \\
St. Marks Estuary & 0.80 & 0.61 \\
Flensburg Fjord & 0.73 & 0.76 \\
Bahia Falsa & 0.60 & 0.67 \\
Ythan Estuary & 0.47 & 0.61 \\
Carpinteria Salt Marsh & 0.60 & 0.63 \\
Otago Harbor & 0.53 & 0.66 \\
Estero de Punta Banda & 0.67 & 0.66 \\
Sylt Tidal Basin & 0.67 & 0.60 \\
\hline
\end{tabular}

other food webs (Fig. 3). The consistently lower MEs for the Tagus webs for the properties Clust and Can indicate that clustering and cannibalism is higher in those webs compared to the other webs. In addition, the consistently lower MEs for the Tagus webs for VulSD and LinkSD indicates that variability in the number of links per species (LinkSD: normalized standard deviation of links) is greater than in the other webs and is largely driven by higher variability in the number of consumers per species (VulSD: normalized standard deviation of mean vulnerability). In the case of MaxSim, the mean maximum trophic similarity of species, the Tagus webs have MEs that fall at the upper bound of the $95 \%$ confidence intervals of MEs across the other webs, indicating lower MaxSim in the Tagus webs. In general, the Tagus Estuary webs were more poorly fit by the niche model than the other estuary/intertidal webs. This is indicated both by higher proportions of the MEs for the 14 model properties being $>|1|$ in the Tagus webs, as well as the proportion of links correctly predicted by a probabilistic version of the niche model being lower in the Tagus webs than the other webs (Table 6). The overall fit of the niche model in terms of MEs does improve through time for the Tagus webs.

\section{DISCUSSION}

From the 1970 s to the present, only 3 relatively high trophic level fish species have been lost in the Tagus Estuary system: European flounder Platichthys flesus, sprat Sprattus sprattus, and fivebeard rockling Ciliata mustela. No further loss of fish species is predicted to occur due to climate change over the next century. Six relatively high trophic level fishes have been added along with an invasive crab, and 9 more fishes, including lower trophic level herbivores, are predicted to invade the system by the 2100s. Because more fish species will be added than lost, this estuarine system is predicted to increase in species richness due to climate change over the next century. Various authors have pointed out that due to the interaction of large-scale biogeographic patterns and climate change, an increase in species' richness at higher latitudes is expected due to pole-ward latitudinal range shifts (Hiddink \& ter Hofstede 2008, ter Hofstede et al. 2010, Vinagre et al. 2011). This is caused by the combination of increasing water temperature and the biogeographic trend of increasing species richness with decreasing latitude. The effect of this interaction has already been reported for the North Sea (Hiddink \& ter Hofstede 2008) and various European estuaries (Nicolas et al. 2011).

Differences in species richness among the past, present, and future Tagus food webs (mostly due to additions, not extinctions) did not coincide with obvious changes in food web structure. In contrast to the Tagus Estuary, where species richness was predicted to change by $16 \%$, the Mediterranean Sea is predicted to lose $21 \%$ of species (54 out of 256), with concurrent drastic effects on connectance and generality (Albouy et al. 2014). Elsewhere, Kortsch et al. (2015) found that adding 4 fish species (2.5\%) to an Artic topological food web also resulted in only minor changes in food web properties. These results support the conclusion of Dunne et al. $(2002 b, 2008)$ that $\sim 20 \%$ or more of taxa and their links need to be removed before significant structural alterations are evident.

In addition to an overall increase in the number of taxa in the Tagus Estuary, we observe that the number of trophic links in the future food web is also expected to increase, along with the mean generality of species. Connectance, the fraction of possible trophic links that are realized, is predicted to drop slightly from the present to the future. The structure of the food web, however, is likely to be quite insensitive to these changes. The top 10 taxa in terms of generality, trophic level, and path length change very little between past, present, and future. Furthermore, almost none of the species that are lost or added belong in the top 10 of these properties, meaning that such species are not likely to disturb the established food web topology. When the niche model 
is used to normalize comparisons of food web properties given the size and complexity of the webs (Dunne et al. 2004, 2013), most trophic structure properties examined do not change from the past to present to future versions of the Tagus food web. Although a signal is not detected in the current data, if herbivorous fish continue to preferentially invade the system in the future under climate change (Vinagre et al. 2011), that could eventually push the mean trophic level down for the whole food web and potentially affect other properties as well as ecosystem functioning. Elsewhere, tropical ecosystems have a higher proportion of herbivorous fish (Floeter et al. 2004, 2005) compared to the Tagus Estuary, and the likely addition of herbivorous fish to the Tagus Estuary over the next century could signify the beginning of a shift from a temperate/subtropical to a subtropical/tropical ecosystem. However, given that the Tagus Estuary is a very turbid system with reduced macroalgal presence, such herbivorous fish are not likely to proliferate into large populations, so accentuated population dynamics changes are not to be expected if the main abiotic characteristics of the system are preserved.

The Tagus Estuary food webs have a network structure that for the most part falls within what is observed for other estuarine and intertidal food webs, although they are at the low end of levels of connectance for these types of webs. There are a few properties of the Tagus webs that appear to significantly differ from many previously published food webs, particularly higher clustering, higher cannibalism, and higher variability in vulnerability in total links. The relatively higher level of cannibalism in the Tagus Estuary compared to the other estuarine food webs may be due in part to this area being an important nursery ground for many species (Costa \& Bruxelas 1989). Cannibalism is usually the result of a wide size gap between predatory adults and juveniles and/or larvae of the same species, and this should be more common in areas where early life stages concentrate, like nursery areas. Estuarine waters attract larval and juvenile fish because of their warm waters and richness in macrobenthic prey (Haedrich 1983), particularly in spring and summer. This, however, also attracts the adults of some species, which end up feeding on young of their own species. The Tagus Estuary's area is among the largest (in area) considered in the present study, which may also explain the higher levels of cannibalism. The higher levels of variability in vulnerability than expected for the Tagus versus other estuarine/ intertidal webs, and for all of those webs in relation to niche model predictions, may be due to a bias that commonly occurs in data compiled for estuarine systems favoring high trophic level organisms (e.g. fish) and overlooking their predators and parasites, but highly resolving the consumers of lower trophic level taxa (Dunne et al. 2004). In general, the niche model and the probabilistic niche models provided poorer fits to the trophic organization of the Tagus food webs compared to other estuary/intertidal food webs, and even more so compared to other food webs analyzed previously. However, much of this may be due to the reduced fit of those models with increasing species richness of the food webs analyzed.

Although the Tagus Estuary webs were more poorly fit by both the standard niche model and the probabilistic niche model than other intertidal webs examined (Table 6), it has been previously noted that there is a general trend of increasingly poor fit of the niche model and the probabilistic niche model with increasing $S$ (Williams \& Martinez 2008, Williams \& Purves 2011, Dunne et al. 2013, 2014, Wood et al. 2015), and the Tagus Estuary food webs fit these general patterns (Fig. 4). The poorer fit of the niche models to the Tagus Estuary food webs appears to be partly due to the relatively high trophic species richness of these webs compared to other webs.

Our analyses show the important roles that humans play in the Tagus food web, which has been the location of extensive fisheries for thousands of years (Baeta et al. 2005). In particular, as also observed for human hunter-gatherers in the intertidal and nearshore marine food webs of the Sanak Archipelago of the Aleutian Islands (Dunne et al. 2016), humans are 'super-generalists' in the Tagus Estuary food web, feeding on more taxa than other predators. However, humans are even more extreme outliers in the Tagus Estuary food web, feeding on a higher percentage of available prey and with a bigger gap between them and the next most general consumer in the past and present webs, compared to humans of the Sanak Islands. This is likely due to the Sanak Islands food webs including non-industrial hunting, fishing, and gathering, whereas the Tagus Estuary food web also includes modern commercial fishing.

The percentage of available prey that humans feed on in the Tagus Estuary is predicted to increase into the future due to changes in the food web from climate change. Many of the new species predicted to colonize the Portuguese coast in the future have the potential to become highly commercial species because they are already the target of important fisheries off the African West coast (Vinagre et al. 2011). Among these are the Cunene horse mackerel Tra- 

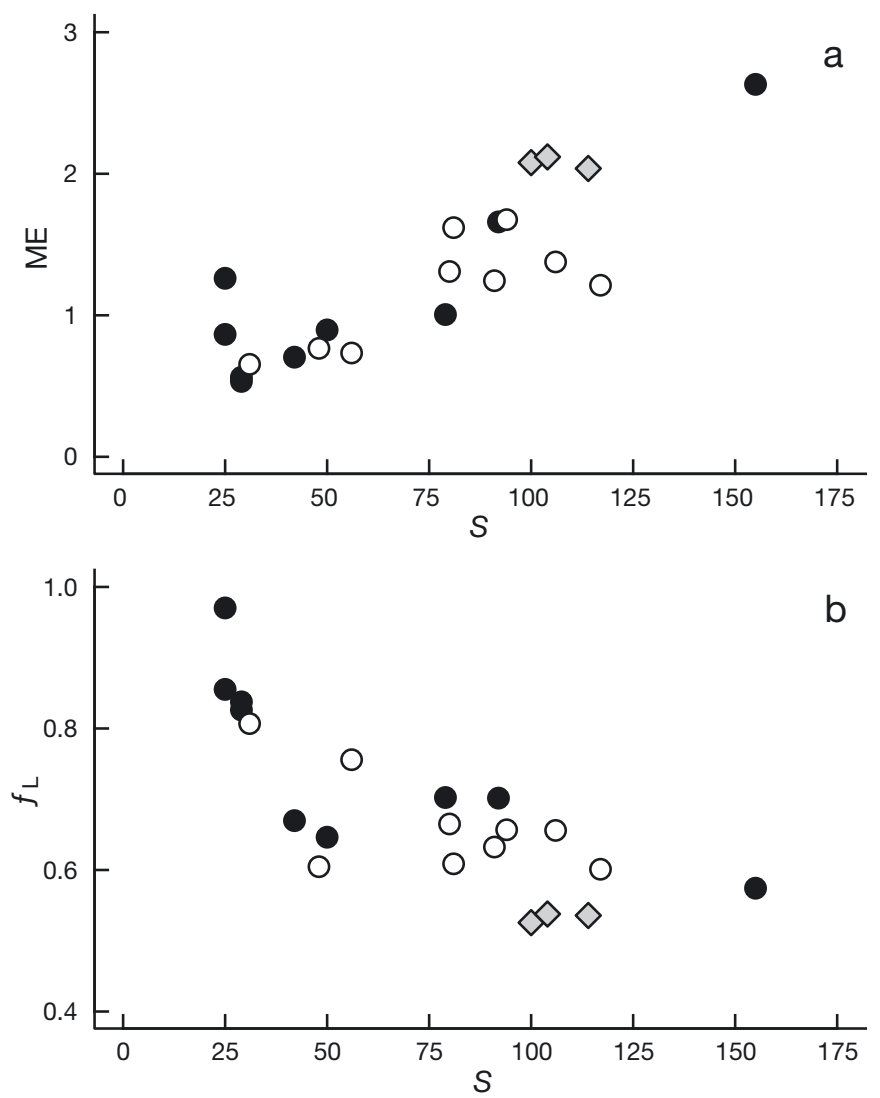

Fig. 4. Scale dependence of standard niche model and probabilistic niche model (PNM) results. (a) Mean absolute niche model error (ME) across 14 food web properties and (b) fraction of links $\left(f_{\mathrm{L}}\right)$ predicted by the 1-dimensional probabilistic niche model as a function of trophic species richness $(S)$. Grey diamonds show results for the 3 Tagus Estuary food webs. Open circles show results for 9 estuarine/intertidal food webs. Solid circles show results for 9 previously studied non-estuarine/intertidal food webs (Bridge Brook Lake, Skipwith Pond, Benguela Marine, Coachella Desert, St. Martin Island, Caribbean Reef, NE U.S. Shelf Marine, Little Rock Lake, El Verde Rain Forest; Dunne et al. 2004)

churus trecae and the Bonga shad Ethmalosa fimbriata. Two other species of shad used to be fished in the Tagus Estuary, the Allis shad Alosa alosa and the Twaite shad Alosa fallax. These supported fishing communities that depended mostly on these species. Shad fisheries collapsed due to the construction of barriers to the spawning migration towards freshwater in the 1950s (Costa et al. 2001). The new shad species, which are predicted to colonize the Tagus Estuary, can spawn in waters with a salinity of 3.5 to $38 \mathrm{ppt}$. This means that they do not necessarily need to migrate upriver and thus will probably be able to maintain populations in the estuary despite the existing barriers. Thus, there is the potential for a comeback of shad fisheries to the Tagus estuary.
One of the most important changes predicted to occur in the Tagus Estuary food web under future climate change will be the addition of a highly omnivorous shark, the milkshark Rhizoprionodon acutus. Second only to humans in number of likely consumer links (42 vs. 52 out of 138 taxa), this shark has a maximum length of $1.75 \mathrm{~m}$ and feeds roughly on the same prey as humans. Its only predator will be humans because larger sharks that prey on this species in its native range are not predicted to colonize this area in the timeframe analyzed here. Another invulnerable 'super-generalist' with a similar diet to humans might compete with humans for prey species and could have an important impact upon the abundance of species that are already under fishing pressure. The super-generalist milkshark may also have cascading top-down effects on the food web dynamics, particularly if the Tagus Estuary is as highly regulated by top-down forces as many other marine communities (Shurin et al. 2006).

While losses and additions of fish species to the Tagus Estuary food web are well supported by literature and current knowledge, similar losses and additions of species will potentially also happen among the macrozoobenthos, zooplankton, phytoplankton, and other taxa that are presented in a highly aggregated way in the present study. Such alterations in species compositions may have important effects on the Tagus Estuary food web structure and function which we are unable to resolve based on current knowledge. Topological food webs, such as the ones studied here, do not capture the potential adaptability of predators (e.g. prey-switching and the intrinsic variability of species interactions) in a changing community (Staniczenko et al. 2010, Poisot et al. 2015). Those potential effects may remain unpredictable until detailed diet and behavior studies are conducted and more highly and evenly resolved food webs can be assembled. The apparent insensitivity of Tagus food web structure to climate change-induced losses and additions of various fish taxa may shift as we gain more detailed understanding of the sensitivity of fish and, particularly, non-fish components of the food web to climate change. Future studies that go beyond food web topology to encompass issues such as interaction strength, trophic rewiring, and the vulnerability of low trophic level taxa will also bring new insights into the effects of climate warming in the Tagus Estuary food web.

Acknowledgements. This study had the support of the Portuguese Science Foundation 'Fundação para a Ciência e a Tecnologia' (FCT) through a researcher position awarded to 
C.V. (Investigador FCT), the projects PTDC/MAR-EST/2141/ 2012, PTDC/BIA-BMA/28304/2017 and the strategic project UID/MAR/04292/2019 granted to MARE.

\section{LITERATURE CITED}

Able KW (2005) A re-examination of fish estuarine dependence: evidence for connectivity between estuarine and ocean habitats. Estuar Coast Shelf Sci 64:5-17

Albouy C, Velez L, Coll M, Colloca F, Le Loc'h F, Mouillot D, Gravel D (2014) From projected species distribution to food-web structure under climate change. Glob Change Biol 20:730-741

Baeta F, Pinheiro A, Corte-Real M, Costa JL, Almeida PR, Cabral H, Costa MJ (2005) Are the fisheries in the Tagus estuary sustainable? Fish Res 76:243-251

*Biand F, Cohen JE (1984) Community food webs have scale-invariant structure. Nature 307:264-266

Brogueira MJ, Oliveira MR, Cabeçadas G (2007) Phytoplankton community structure defined by key environmental variables in Tagus estuary, Portugal. Mar Environ Res 64:616-628

Cabral HN, Costa MJ (1999) On the occurrence of the Chinese mitten crab, Eriocheir sinensis, in Portugal (Decapoda, Brachyura). Crustaceana 72:55-58

* Cabral HN, Costa MJ, Salgado JP (2001) Does the Tagus estuary fish community reflect environmental changes? Clim Res 18:119-126

Camacho J, Guimerà R, Amaral LAN (2002) Robust patterns in food web structure. Phys Rev Lett 88:228102

* Chaínho P, Chaves ML, Costa JL, Costa MJ, Dauer DM (2008) Use of multimetric indices to classify estuaries with different hydromorphological characteristics and different levels of human pressure. Mar Pollut Bull 56: 1128-1137

* Cohen JE (1994) Marine and continental food webs: three paradoxes? Philos Trans R Soc Lond B Biol Sci 343:57-69

Costa MJ, Bruxelas A (1989) The structure of fish communities in the Tagus estuary, Portugal, and its role as a nursery for commercial fish species. Sci Mar 53:561-566

Costa MJ, Almeida PR, Domingos IM, Costa JL, Correia MJ, Chaves ML, Teixeira CM (2001) Present status of the main shads' populations in Portugal. Bull Fr Peche Piscicult 362/363:1109-1116

* Costa MJ, Vasconcelos R, Costa JL, Cabral HN (2007) River flow influence on the fish community of the Tagus estuary (Portugal). Hydrobiologia 587:113-123

Crabtree SA, Vaughn LJS, Crabtree NT (2017) Reconstructing Ancestral Pueblo food webs in the southwestern United States. J Archaeol Sci 81:116-127

* Dunne JA, Williams RJ, Martinez ND (2002a) Food-web structure and network theory: the role of connectance and size. Proc Natl Acad Sci USA 99:12917-12922

* Dunne JA, Williams RJ, Martinez ND (2002b) Network structure and biodiversity loss in food webs: robustness increases with connectance. Ecol Lett 5:558-567

Dunne JA, Williams RJ, Martinez ND (2004) Network structure and robustness of marine food webs. Mar Ecol Prog Ser 273:291-302

* Dunne JA, Williams RJ, Martinez ND, Wood RA, Erwin DH (2008) Compilation and network analyses of Cambrian food webs. PLOS Biol 6:e102

Dunne JA, Lafferty KD, Dobson AP, Hechinger RF and others (2013) Parasites affect food web structure primarily through increased diversity and complexity. PLOS Biol 11:e1001579

* Dunne JA, Labandeira CC, Williams RJ (2014) Highly resolved early Eocene food webs show development of modern trophic structure after the end-Cretaceous extinction. Proc Biol Sci 281:20133280

* Dunne JA, Maschner H, Betts MW, Huntly N, Russell R, Williams RJ, Wood SA (2016) The roles and impacts of human hunter-gatherers in North Pacific marine food webs. Sci Rep 6:21179

Durieux EDH, Marques JF, Sasal P, Bégout ML, Cabral HN (2007) Comparison of Solea solea macroparasites between two nursery-continental shelf systems in the Bay of Biscay and the Portuguese coast. J Fish Biol 70:1921-1930

Elliott M, Hemingway K (2002) Fishes in estuaries. Blackwell, London

*FFloeter SR, Ferreira CEL, Domici-Arosemena A, Zalmon IR (2004) Latitudinal gradients in Atlantic reef fish communities: trophic structure and spatial use patterns. J Fish Biol 64:1680-1699

Floeter SR, Behrens MD, Ferreira CEL, Paddack MJ, Horn $\mathrm{MH}$ (2005) Geographical gradients of marine herbivorous fishes: patterns and processes. Mar Biol 147:1435-1447

Gaudêncio MJ, Cabral HN (2007) Trophic structure of macrobenthos in the Tagus estuary and adjacent coastal shelf. Hydrobiologia 587:241-251

Haedrich RL (1983) Estuarine fishes. In: Ketchum B (ed) Ecosystems of the world, 26. Estuarine and enclosed seas. Elsevier, Amsterdam, p 183-207

* Hiddink JG, ter Hofstede R (2008) Climate induced increases in species richness of marine fishes. Glob Change Biol 14:453-460

KHuxham M, Beany S, Raffaelli D (1996) Do parasites reduce the chances of triangulation in a real food web? Oikos 76 : 284-300

Kortsch S, Primicerio R, Fossheim M, Dolgov AV, Aschan M (2015) Climate change alters the structure of arctic marine food webs due to poleward shifts of boreal generalists. Proc R Soc B 282:20151546

K Krause AE, Frank KA, Mason DM, Ulanowicz RE, Taylor WW (2003) Compartments revealed in food-web structure. Nature 426:282-285

Lafferty KD, Dobson AP, Kuris AM (2006) Parasites dominate food web links. Proc Natl Acad Sci USA 103:11211-11216

* Link J (2002) Does food web theory work for marine ecosystems? Mar Ecol Prog Ser 230:1-9

* Lotze HK, Coll M, Dunne JA (2011) Historical changes in marine resources, food-web structure and ecosystem functioning in the Adriatic Sea, Mediterranean. Ecosystems 14:198-222

* Marques SC, Azeiteiro UM, Marques JC, Neto JM, Pardal MA (2006) Zooplankton and ichthyoplankton communities in a temperate estuary: spatial and temporal patterns. J Plankton Res 28:297-312

McLusky DS (1981) The estuarine ecosystem. Wiley, New York, NY

McLusky DS, Elliott M (2004) The estuarine ecosystem: ecology, threats and management. Oxford University Press, Oxford

*McLusky DS, Elliott M (2007) Transitional waters: a new approach, semantics or just muddying the waters? Estuar Coast Shelf Sci 71:359-363

*Moreira F (1997) The importance of shorebirds to energy fluxes in a food web of a south European estuary. Estuar Coast Shelf Sci 44:67-78 
Moreira F (1999) On the use by birds of intertidal areas of the Tagus: implications for management. Aquat Ecol 33: 301-309

Mouritsen KN, Poulin R, McLaughlin JP, Thieltges DW (2011) Food web including metazoan parasites for an intertidal ecosystem in New Zealand. Ecology 92:2006

Nakicenovic N, Alcamo J, Davis G, de Vries B and others (2000) Emission scenarios. A special report of Working Group III of the IPCC. Cambridge University Press, Cambridge

Nicolas D, Chaalali A, Drouineau H, Lobry J, Uriarte A, Borja A, Boet P (2011) Impact of global warming on European tidal estuaries: some evidence of northward migration of estuarine fish species. Reg Environ Change 11:639-649

Petchey OL, Timon McPhearson P, Casey TM, Morin PJ (1999) Environmental warming alters food-web structure and ecosystem function. Nature 402:69-72

Petchey OL, Beckerman AP, Riede JO, Warren PH (2008) Size, foraging, and food web structure. Proc Natl Acad Sci USA 105:4191-4196

* Petchey OL, Brose U, Rall BC (2010) Predicting the effects of temperature on food web connectance. Philos Trans R Soc Lond B Biol Sci 365:2081-2091

Poisot T, Stouffer DB, Gravel D (2015) Beyond species: why ecological interaction networks vary through space and time. Oikos 124:243-251

Ribeiro L, Brotas V, Mascarell G, Couté A (2003) Taxonomic survey of the microphytobenthic communities of two Tagus estuary mudflats. Acta Oecol 24:S117-S123

Shurin JB, Gruner DS, Hillebrand H (2006) All wet or dried up? Real differences between aquatic and terrestrial food webs. Proc Biol Sci 273:1-9

Sousa-Dias A, Melo RA (2008) Long-term abundance patterns of macroalgae in relation to environmental variables in the Tagus Estuary (Portugal). Estuar Coast Shelf Sci 76:21-28

Staniczenko PP, Lewis OT, Jones NS, Reed Tsochas F (2010) Structural dynamics and robustness of food webs. Ecol Lett 13:891-899

Stouffer DB, Camacho J, Guimerà R, Ng CA, Amaral LAN (2005) Quantitative patterns in the structure of model and empirical food webs. Ecology 86:1301-1311

Stouffer DB, Camacho J, Jiang W, Amaral LAN (2007) Evidence for the existence of a robust pattern of prey selection in food webs. Proc Biol Sci 274:1931-1940

ter Hofstede R, Hiddink JG, Rijnsdorp AD (2010) Regional warming changes fish species richness in the eastern North Atlantic Ocean. Mar Ecol Prog Ser 414:1-9

* Thieltges DW, Reise K, Mouritsen KN, McLaughlin JP, Poulin R (2011) Food web including metazoan parasites for a tidal basin in Germany/Denmark. Ecology 92: 2005

Editorial responsibility: Stephen Wing,

Dunedin, New Zealand
Thompson RM, Mouritsen KN, Poulin R (2005) Importance of parasites and their life cycle characteristics in determining the structure of a large marine food web. J Anim Ecol 74:77-85

* Tolhurst TJ, Jesus B, Brotas V, Paterson DM (2003) Diatom migration and sediment armouring - an example from the Tagus Estuary, Portugal. Hydrobiologia 503:183-193

* Vinagre C, Costa MJ (2014) Estuarine-coastal gradient in food web network structure and properties. Mar Ecol Prog Ser 503:11-21

*Vinagre C, Fonseca V, Cabral H, Costa MJ (2006) Habitat suitability index models for the juvenile soles, Solea solea and Solea senegalensis: defining variables for management. Fish Res 82:140-149

* Vinagre C, Costa MJ, Cabral HN (2007) Impact of climate and hydrodynamics in sole larval immigration into the Tagus estuary. Estuar Coast Shelf Sci 75:516-524

Vinagre C, Duarte Santos F, Cabral HN, Costa MJ (2009) Impact of climate and hydrology on juvenile fish recruitment towards estuarine nursery grounds in the context of climate change. Estuar Coast Shelf Sci 85: 479-486

*Vinagre C, Duarte Santos F, Cabral HN, Costa MJ (2011) Impact of climate warming upon the fish assemblages of the Portuguese coast under different scenarios. Reg Environ Change 11:779-789

* Vinagre C, Costa MJ, Dunne JA (2017) Effect of spatial scale on the network properties of estuarine food webs. Ecol Complex 29:87-92

Williams RJ (2010) Network3D software. Microsoft Research, Cambridge

Williams RJ, Martinez ND (2000) Simple rules yield complex food webs. Nature 404:180-183

*Williams RJ, Martinez ND (2004) Limits to trophic levels and omnivory in complex food webs: theory and data. Am Nat 163:458-468

*Williams RJ, Martinez ND (2008) Success and its limits among structural models of complex food webs. J Anim Ecol 77:512-519

*Williams RJ, Purves DW (2011) The probabilistic niche model reveals substantial variation in the niche structure of empirical food webs. Ecology 92:1849-1857

Wood SA, Russell R, Hanson D, Williams RJ, Dunne JA (2015) Effects of spatial scale of sampling on food web structure. Ecol Evol 5:3769-3782

*Woodward G, Benstead JP, Beveridge OS, Blanchard J and others (2010) Ecological networks in a changing climate. Adv Ecol Res 42:71-138

Zander CD, Josten N, Detloff KC, Poulin R, McLaughlin JP, Thieltges DW (2011) Food web including metazoan parasites for a brackish shallow water ecosystem in Germany and Denmark. Ecology 92:2007

Submitted: August 30, 2018; Accepted: March 12, 2019

Proofs received from author(s): April 29, 2019 